\title{
Efeitos da enramicina e da monensina sódica no consumo de matéria seca, na fermentação ruminal e no comportamento alimentar em bovinos alimentados com dietas com alto nível de concentrado
}

\author{
Luiz Felipe de Onofre Borges ${ }^{1}$, Roberta Passini $^{2}$, Paula Marques Meyer ${ }^{3}$, Alexandre Vaz \\ Pires $^{4}$, Paulo Henrique Mazza Rodrigues ${ }^{5,6}$
}

\author{
${ }^{1}$ Mestrando do Departamento de Nutrição e Produção Animal - FMVZ/USP. \\ 2 Unidade de Ciências Exatas e Tecnológicas - UnUCET - Universidade Estadual de Goiás. \\ ${ }^{3}$ Analista Agropecuário do Instituto Brasileiro de Geografia e Estatística - IBGE. \\ ${ }^{4}$ Escola Superior de Agricultura "Luiz de Queiroz" - ESALQ/USP. \\ ${ }^{5}$ Departamento de Nutrição e Produção Animal - FMVZ/USP, Av. Duque de Caxias Norte, 225 - CEP:13630-000, Pirassununga - SP. \\ ${ }^{6}$ Bolsista Produtividade em Pesquisa do CNPq.
}

RESUMO - Estudaram-se os efeitos da administração de enramicina e monensina sódica no consumo de matéria seca (MS), na fermentação ruminal e no comportamento alimentar de bovinos. Doze fêmeas bovinas não-gestantes e não-lactantes (675 $\pm 63 \mathrm{~kg}$ PC) foram distribuídas inteiramente ao acaso em três tratamentos, formados por um grupo controle, um grupo tratado com enramicina e outro tratado com monensina. Os animais foram alimentados com dieta contendo $60 \%$ de concentrado (milho, farelo de soja e minerais) e $40 \%$ de volumoso (cana-de-açúcar). A enramicina foi administrada na dose de $20 \mathrm{mg} / \mathrm{animal} /$ dia e a monensina na dose de $300 \mathrm{mg} / \mathrm{animal} / \mathrm{dia}$. O experimento teve duração total de 21 dias, de modo que o 21 o dia foi utilizado para coleta de líquido ruminal, realizada às 0 , 2, 4, 6, 8, 10 e 12 horas após a primeira refeição. A monensina aumentou a concentração total de AGV 12 horas após a alimentação, em relação aos demais tratamentos, e diminuiu a relação acético:propiônico nos tempo 0 e 6 horas, em relação à enramicina, mas não em relação ao controle. Nenhum dos antibióticos testados alterou a proporção molar dos ácidos acético, propiônico ou butírico nem o pH e a concentração ruminal de nitrogênio amoniacal. Os antibióticos também não alteraram o consumo de MS ou o comportamento ingestivo, avaliado nas atividades de alimentação, ruminação e ócio.

Palavras-chave: ácidos graxos voláteis, consumo, ionóforos, não-ionóforos, ruminantes

\section{Effects of enramycin and sodium monensin on dry matter intake, ruminal fermentation and alimentary behavior in bovine fed high-concentrate diets}

\begin{abstract}
The objective of this research was to study the effects of enramycin and sodium monensin administration on dry matter intake, ruminal fermentation and alimentary behavior in bovine. Twelve non-pregnant and non-lactating cows (675 kg \pm 63 of BW) were randomly assigned to three treatments: control group, enramycin treated group or monensin treated group. Animals received a diet containing $60 \%$ of concentrates (corn, soybean meal and minerals) and $40 \%$ of forage (sugarcane). Treatments were $20 \mathrm{mg} /$ animal/day of enramycin and $300 \mathrm{mg} /$ animal/day of monensin. Trial lasted 21 days, and at the $21^{\text {st }}$ was used for ruminal fluid sampling at $0,2,4,6,8,10$ and 12 hours after $1^{\text {st }}$ meal. Monensin increased total VFA concentration $12 \mathrm{~h}$ after feeding in relation to others treatments and decreased the acetic:propionic ratio at times 0 and $6 \mathrm{~h}$, in relation to enramycin, but not when compared to control. The two ionophores tested did not influence the molar proportion of acetic, propionic or butyric acids, $\mathrm{pH}$, ammoniacal-N concentration, or DM intake and intake behavior, evaluated during activities of feeding, rumination and idleness.
\end{abstract}

Key Words: intake, ionophores, non-ionophores, ruminants, volatile fatty acids

\section{Introdução}

Segundo Bergen \& Bates (1984), constitui-se uma antiga busca dos nutricionistas de ruminantes a melhora da eficiência da fermentação ruminal, por meio do aumento da produção de ácido propiônico, da diminuição da metanogênese ou da diminuição da proteólise e deaminação de proteínas no rúmen. Durante muito tempo, procurou-se atingir esses objetivos por meio da manipulação da dieta, porém, nas últimas décadas um grande número de compostos químicos tem sido testado para os mesmos fins. Ionóforos são uma classe desses compostos que teve considerável 
sucesso como aditivo alimentar. O uso de ionóforos como a monensina em animais data da década de 70 com o objetivo de aumentar a eficiência de utilização de alimentos (Goodrich et al.,1984; Russell \& Strobel, 1989).

A maior parte dos substratos energéticos na dieta dos ruminantes constitui-se de carboidratos fermentados pelos microrganismos ruminais, produzindo ácidos graxos voláteis (AGV), metano e dióxido de carbono. Os AGV produzidos pela fermentação microbiana são absorvidos e servem como a maior fonte energética para os ruminantes (Spears, 1990). Os ionóforos são substâncias de pequeno peso molecular que, ligadas a íons de vários minerais, se movimentam por intermédio das membranas celulares (Lucci, 1997). Causam diminuição do crescimento de bactérias gram-positivas, alterando, dessa forma, a fermentação ruminal (NRC, 1989) e reduzindo as perdas energéticas via metano (Chalupa, 1977).

Van Der Merwe et al. (2001) citam também o uso de antibióticos não-ionóforos, como a avoparcina, flavomicina, tilosina, bacitracina e virginamicina, que promovem o crescimento do animal e alteram as características fermentativas do rúmen.

Com os recentes acidentes ocorridos no Brasil envolvendo a monensina e resultando na morte de cavalos intoxicados (Bezerra et al., 1999), tem-se observado a busca por produtos mais seguros e tão eficientes quanto este ionóforo. O produto testado neste experimento foi a enramicina, um antibiótico não-ionóforo, promotor de crescimento muito usado em aves e suínos. Possui estrutura polipeptídica e é produzido a partir da cepa de Streptomyces fungicidus (Kawakami \& Nagai, 1971). Objetivou-se estudar os efeitos da administração da enramicina, em comparação à monensina sódica, na fermentação ruminal, no consumo de matéria seca e no comportamento alimentar de bovinos.

\section{Material e Métodos}

O trabalho foi conduzido nas dependências do Departamento de Nutrição e Produção Animal da Faculdade de Medicina Veterinária e Zootecnia da Universidade de São Paulo (Campus de Pirassununga).

Foram utilizadas doze fêmeas bovinas mestiças, nãolactantes e não-gestantes, portadoras de cânulas ruminais e com $675 \pm 63 \mathrm{~kg}$ de peso vivo ao início do experimento. $\mathrm{O}$ estábulo utilizado possuía baias individuais com cochos de cimento, bebedouros automáticos, piso emborrachado e ventiladores suspensos no teto, que eram ligados nas horas mais quentes do dia. O delineamento experimental foi o inteiramente casualizado com três tratamentos, corres- pondentes ao controle negativo (ausência de antibiótico), tratado (enramicina) e controle positivo (monensina sódica). Para o tratamento com enramicina, foi utilizado o produto comercial Enradin F80 (Coopers Brasil Ltda.) na dose de $20 \mathrm{mg}$ de enramicina/animal/dia (250 mg de Enradin F80/animal/dia ou 1,5 ppm de princípio ativo na matéria seca da dieta). Para o tratamento com monensina foi utilizado o produto comercial Rumensin (Elanco) na dose de $300 \mathrm{mg}$ de monensina sódica/animal/dia (3,0 g de Rumensin/animal/dia). Esta dose correspondeu à concentração de 21,7 ppm de monensina sódica na matéria seca da dieta, muito próxima da média entre 11,0 e 33,0 ppm recomendada pela empresa que comercializa o produto. Cada produto foi pesado separadamente em balança analítica e depois acondicionado em envelopes confeccionados em papel absorvente, administrados diariamente no interior do rúmen, através da fístula ruminal e misturados ao conteúdo ruminal por meio de agitação manual. A dose diária foi dividida em duas vezes, correspondendo ao momento das refeições.

Os animais foram alimentados duas vezes ao dia, às 8 e 16 h, com dieta contendo $60 \%$ de concentrados e $40 \%$ de volumoso (Tabela 1), fornecida na forma de mistura completa, permitindo-se $10 \%$ de sobras.

O período experimental constituiu-se de 21 dias, os primeiros 16 para adaptação dos animais às dietas, os cinco seguintes (do $17^{\circ}$ ao $21^{\circ} \underline{ }$ dia) para avaliação do consumo de MS e o $21^{\underline{o}}$ para a coleta de líquido ruminal e avaliação do comportamento ingestivo. Amostras de líquido ruminal

Tabela 1 - Composição das rações experimentais

\begin{tabular}{|c|c|}
\hline Ingrediente & $(\% \mathrm{MS})$ \\
\hline Cana-de-açúcar & 40,0 \\
\hline Grãos de milho moído & 39,8 \\
\hline Farelo de soja & 18,4 \\
\hline Calcário calcítico & 0,3 \\
\hline Sal branco $(\mathrm{NaCl})$ & 0,5 \\
\hline Mistura mineral ${ }^{1}$ & 1,0 \\
\hline \multicolumn{2}{|l|}{ Composição nutricional } \\
\hline MS (\%) & 55,1 \\
\hline $\mathrm{PB}(\% \mathrm{MS})$ & 13,5 \\
\hline PDR $(\% \text { da PB })^{2}$ & 64,5 \\
\hline PNDR (\% da PB) $)^{2}$ & 35,5 \\
\hline FDA (\% MS) & 18,5 \\
\hline FDN (\% MS) & 27,7 \\
\hline $\mathrm{EE}(\% \mathrm{MS})$ & 2,2 \\
\hline $\mathrm{EL}_{\mathrm{l}}(\mathrm{Mcal} / \mathrm{kg} \mathrm{MS})^{2}$ & 1,55 \\
\hline $\mathrm{Ca}(\% \mathrm{MS})$ & 0,39 \\
\hline P (\% MS) & 0,31 \\
\hline
\end{tabular}


foram coletadas às 0, 2, 4, 6, 8, 10 e 12 horas após a primeira refeição do dia, em três diferentes locais do rúmen, totalizando aproximadamente $500 \mathrm{~mL}$ em cada coleta. Para isso, utilizou-se tubo de cobre perfurado (1,2 $\mathrm{m}$ de comprimento e 1,0 cm de diâmetro) ligado, por meio de mangueiras de silicone e um Kitassato, a uma bomba de vácuo. Em seguida, $50 \mathrm{~mL}$ do líquido ruminal foram centrifugados, sem sofrer filtragem, a 2000 FCR (força centrífuga relativa) por 15 minutos e $1 \mathrm{~mL}$ do sobrenadante foi adicionado a $0,2 \mathrm{~mL}$ de ácido fórmico e congelado para posterior determinação dos AGV. Outros $2 \mathrm{~mL}$ do sobrenadante foram adicionados a $1 \mathrm{~mL}$ de ácido sulfúrico solução $1 \mathrm{~N}$ e congelados a $-20^{\circ} \mathrm{C}$ para determinação do nitrogênio amoniacal. A determinação dos AGV foi realizada por meio de cromatografia gasosa (Erwin et al., 1961) no laboratório de Nutrição Animal da Faculdade de Medicina Veterinária da Universidade de São Paulo (VNP/FMVZ/USP). Para isso, utilizou-se um cromatógrafo a gás (marca Finnigan, modelo 9001) equipado com coluna Megabore da Ohio Valley, modelo OV-351 de 1 Micron, com 30 m de comprimento e 0,53 mm de diâmetro. O número de repetições por amostra foi o necessário para que a diferença entre as leituras fosse inferior a 5\%. A solução padrão foi aplicada a cada dez injeções sucessivas de amostras, de modo a evitar possíveis distorções das leituras decorrentes da contaminação da coluna. A determinação do nitrogênio amoniacal $\left(\mathrm{N}-\mathrm{NH}_{3}\right)$ foi realizada por colorimetria (Foldager, 1977) e o $\mathrm{pH}$ do fluido ruminal em potenciômetro digital portátil.

O comportamento ingestivo foi avaliado observando-se os animais a cada 10 minutos durante as 12 horas após a primeira alimentação do dia. As atividades avaliadas foram divididas em comendo/bebendo, ruminando e em ócio. Os dados foram transformados em porcentagem do tempo total observado.

Os resultados foram analisados por meio do programa computacional Statistical Analysis System (SAS, 1985). Os dados de consumo de matéria seca e comportamento alimentar foram submetidos à análise de variância (PROC GLM do SAS), que separou como única causa de variação o efeito de tratamento. Os dados referentes aos AGV, pH e concentrações de nitrogênio amoniacal no líquido ruminal foram analisados conforme descrito, porém adicionados do fator medidas repetidas no tempo (comando REPEATED do GLM do SAS), referentes aos diversos momentos de colheita entre as refeições. Na ocorrência de interação tempo $\times$ tratamento, a análise de variância dentro de cada tempo foi realizada pelo comando SLICE (GLM do SAS). A separação dos efeitos de tratamento foi realizada pelo teste Tukey, adotando-se o nível de significância de 5\%, exceto quando especificado.

\section{Resultados e Discussão}

O consumo de MS (Tabela 2), que em média foi de 1,87\% do PV, independentemente do tratamento, manteve-se dentro do esperado para a categoria animal estudada. Nenhum dos antibióticos testados alterou o consumo de MS, calculado em quilos/animal/dia, em porcentagem do peso vivo ou em $\mathrm{g} / \mathrm{kg}$ de peso metabólico/dia. Autores como Green et al. (1999), Plazier et al. (2000), Ruiz et al. (2001) e Gallardo et al. (2005), ao utilizarem monensina, também não observaram alterações no consumo de MS. Garcia et al. (2000), utilizando monensina em cabras alimentadas com dieta composta de $50 \%$ de concentrado e $50 \%$ de volumoso (feno de alfafa), e Rodrigues et al. (2001), utilizando monensina em ovinos recebendo 25,50 ou $75 \%$ de concentrado na dieta, também não constataram mudanças no consumo de MS.

Salles \& Lucci (2000), utilizando diferentes níveis de suplementação de monensina e uma dieta predominantemente concentrada para bezerros, constataram comportamento quadrático para o consumo de MS e maior ingestão quando fornecida monensina na proporção de $0,8 \mathrm{mg} / \mathrm{kg}$ de PV (estimado em 14,3 mg de monensina/kg de MS ingerida). Verificaram ainda diminuição da ingestão no nível mais alto de 1,2 mg de monensina/kg de PV (estimado em 22,7 mg de monensina/kg de MS ingerida).

Em ruminantes alimentados com alta proporção de carboidratos rapidamente fermentáveis, os ionóforos reduzem o consumo de alimento e não modificam o ganho de peso, o que implica melhor conversão alimentar. Quando ruminantes são alimentados com dietas com elevadas quantidades de forragem, os ionóforos não reduzem o consumo e melhoram o ganho de peso (Bergen \& Bates, 1984). Entretanto, esses efeitos sobre o consumo não foram confirmados neste experimento.

Resultados de estudos com vacas lactantes ou nãolactantes utilizando-se monensina têm sido variáveis em relação à ingestão de MS e à produção leiteira, provavelmente em virtude das diferenças no estádio de lactação. Segundo Tedeschi et al. (2003), redução no consumo de MS

Tabela 2 - Consumos de matéria seca obtidos dos animais nos tratamentos

\begin{tabular}{lcccccc}
\hline Consumo & \multicolumn{3}{c}{ Tratamento $^{1}$} & & & \\
\cline { 2 - 4 } & $\mathrm{C}$ & $\mathrm{E}$ & $\mathrm{M}$ & Média & $\mathrm{CV}(\%)$ & $\mathrm{P}$ \\
\hline $\mathrm{MS}$ & & & & & & \\
$\mathrm{kg} / \mathrm{dia}$ & 12,1 & 13,8 & 13,8 & 13,2 & 21,9 & $\mathrm{~ns}$ \\
$\% \mathrm{PV}$ & 1,70 & 1,99 & 1,94 & 1,87 & 16,2 & $\mathrm{~ns}$ \\
$\mathrm{~g} / \mathrm{kg} \mathrm{PV} \mathrm{PV}^{0,75}$ & 87,7 & 101,6 & 100,2 & 96,5 & 17,4 & $\mathrm{~ns}$ \\
\hline
\end{tabular}

${ }^{1} \mathrm{C}=$ controle; $\mathrm{E}=$ enramicina; $\mathrm{M}=$ monensina . 
Tabela 3 - Potencial hidrogeniônico $(\mathrm{pH})$, concentração total de ácidos graxos voláteis (AGV), concentração dos ácidos acético ( $\left.\mathrm{C}_{2}\right)$, propiônico $\left(\mathrm{C}_{3}\right)$, butírico $\left(\mathrm{C}_{4}\right)$, relação acético:propiônico $\left(\mathrm{C}_{2} / \mathrm{C}_{3}\right)$ e concentração de nitrogênio amoniacal $\left(\mathrm{N}-\mathrm{NH} \mathrm{H}_{3}\right)$ no rúmen

\begin{tabular}{|c|c|c|c|c|c|c|c|}
\hline & \multicolumn{3}{|c|}{ Tratamento $^{1}$} & Média & $\mathrm{CV}$ & \multicolumn{2}{|c|}{$\mathrm{P}$} \\
\hline $\mathrm{pH}$ & 6,3 & 6,4 & 6,3 & 6,3 & 5,5 & ns & ns \\
\hline $\mathrm{C}_{2}$, \% molar & 66,2 & 67,0 & 64,2 & 65,8 & 6,3 & ns & ns \\
\hline $\mathrm{C}_{3}$, \% molar & 21,6 & 18,8 & 22,0 & 20,8 & 14,1 & ns & ns \\
\hline $\mathrm{C}_{4}, \%$ molar & 12,1 & 14,2 & 13,8 & 13,6 & 25,3 & ns & ns \\
\hline
\end{tabular}

${ }^{1}$ Trat: probabilidade para efeito de tratamento; Trat $\times$ Tempo: probabilidade para efeito de interação tratamento $\times$ tempo.

é uma conseqüência quando os animais se alimentam apenas para suprir suas exigências energéticas. Tanto em vacas secas quanto em vacas lactantes em balanço energético positivo, a inclusão de monensina na dieta pode aumentar a energia disponível por unidade de alimento consumido (Mcal/kg), o que resulta em menor ingestão de MS. Entretanto, quando as vacas estão em balanço energético negativo, durante o início da lactação, esta energia adicional disponível promovida pela monensina é usada para melhorar o desempenho produtivo e/ou reduzir as perdas de reservas corporais.

Considerando os dados independentemente do tempo de amostragem, nenhum dos antibióticos testados afetou a concentração total de ácidos graxos voláteis, a proporção molar de ácido acético, propiônico ou butírico, a relação acético:propiônico, o pH ou a concentração ruminal de nitrogênio amoniacal (Tabela 3). Não houve efeito de interação entre tratamento e tempo, no entanto, ao se avaliarem os efeitos de tratamento dentro de cada tempo, observou-se que a monensina aumentou a concentração total de AGV no tempo 12 horas após a alimentação em relação aos demais tratamentos (Figura 1A) e diminuiu a relação acético:propiônico nos tempo 0 e 6 horas em relação à enramicina, mas não em relação ao grupo controle (Figura 1B).

O padrão de ácidos graxos voláteis como resultado da adição de monensina tem sido bem documentado na literatura em várias espécies de ruminantes. Na maioria das vezes ocorre aumento da concentração de ácido propiônico e diminuição significativa das concentrações dos ácidos acético e butírico (Green et al., 1999), embora os ionóforos proporcionem menor efeito sobre a produção total de ácidos graxos voláteis (Chalupa, 1977).

Do mesmo modo que neste trabalho, Han et al. (2002) não constataram mudanças na concentração total de ácidos graxos voláteis em bovinos tratados com monensina + tilosina. Também Thornton \& Owens (1981), trabalhando

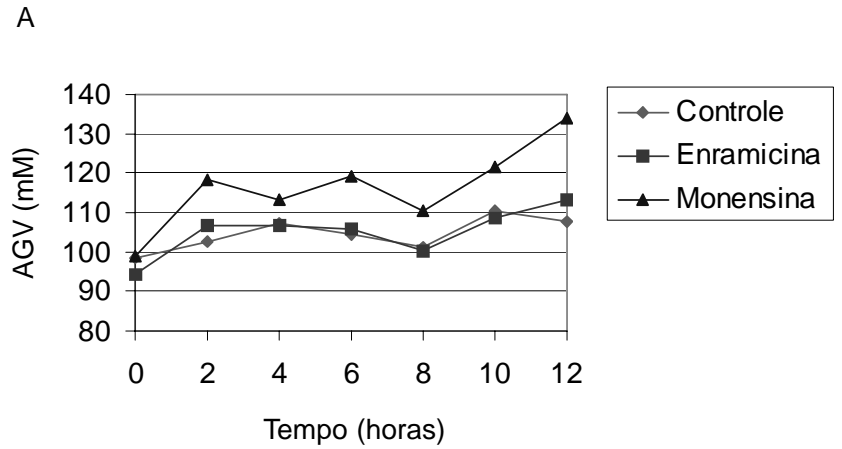

B

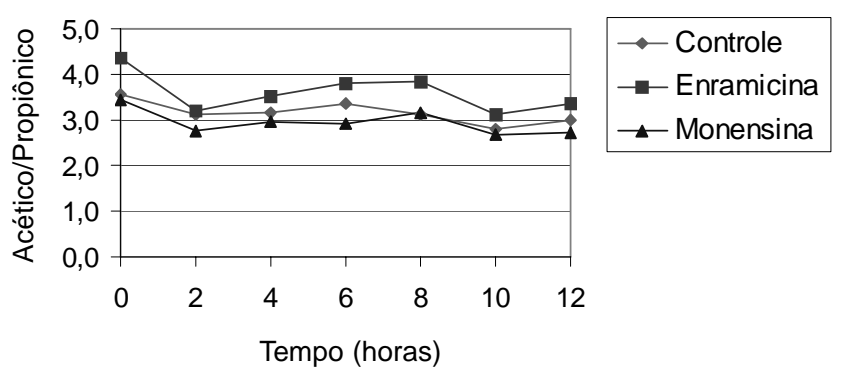

C

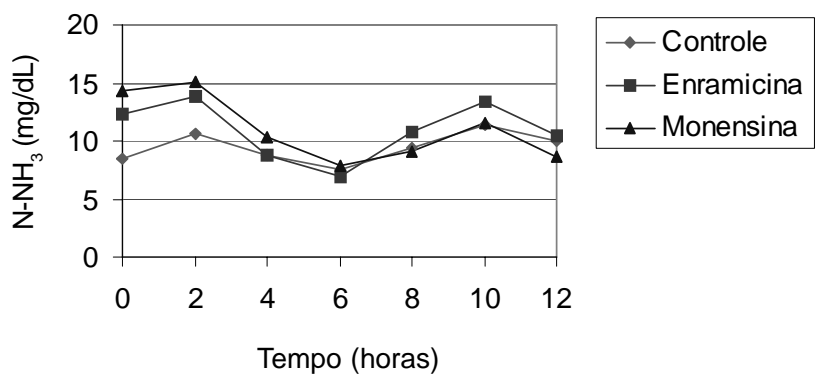

Figura 1 - Concentração total de AGV (mM) (A), relação acético/ propiônico (B) e concentração de nitrogênio amoniacal $(\mathrm{mg} / \mathrm{dL})(\mathrm{C})$ no líquido ruminal no momento e em diferentes períodos após a primeira refeição nos três tratamentos testados. 
com dietas com diferentes níveis de fibra (40 ou 12\% de FDA), não observaram mudanças na concentração total de ácidos graxos voláteis. Muitos autores obtiveram resultados semelhantes aos observados neste experimento, como Baile et al. (1979), Darden et al. (1985), Beede et al. (1986) e Fredrickson et al. (1993).

Broderick (2004), utilizando monensina na dose de 10 mg/kg de MS, não observou alterações significativas nas concentrações desses ácidos orgânicos, resultado ocasionado provavelmente pela baixa dosagem. Prange et al. (1978) reportaram que a adição de $33 \mathrm{mg}$ de monensina/kg de MS em novilhas alimentadas com 70\% de alfafa causou aumento de 19,1 para 24,7\% na concentração molar de ácido propiônico, bem como diminuição de 71,0 para 66,8\% na concentração molar de ácido acético e de ácido butírico de 9,9 para 8,5\%. Ruiz et al. (2001) observaram alterações similares nas concentrações de AGV quando utilizada a dose de $350 \mathrm{mg} /$ dia de monensina (estimada em 17,1 mg de monensina/kg de MS ingerida) em vacas lactantes.

Uma das vantagens do aumento da concentração de ácido propiônico no rúmen é a diminuição de perdas por incremento calórico, uma vez que o ácido acético possui incremento calórico maior que o ácido propiônico (Bergen \& Bates, 1984), o que deve resultar em mais energia para a produção ou menos energia requerida para mantença (Tedeschi et al., 2003).

Observou-se diminuição da relação acético:propiônico nos tempo 0 e 6 h (Figura 1B) no grupo tratado com monensina, em relação à enramicina, mas não em relação ao grupo controle. O efeito da monensina em aumentar a proporção molar de ácido propiônico e diminuir a de ácido acético, comumente observado na literatura, foi explicado por Bergen \& Bates (1984) e tem como causa a presença da enzima fumarato redutase nas bactérias ruminais produtoras de ácido propiônico, proporcionando resistência dessas bactérias à presença da monensina. Russell \& Strobel (1989) condicionaram esta resistência à presença de uma membrana externa nas bactérias gram-negativas agindo como barreira protetora ao acesso dos ionóforos e outras macromoléculas à membrana celular. Entretanto, esses modelos de resistência podem ter exceções, pois, de acordo com Callaway \& Russell (1999), algumas espécies de bactérias gram-negativas precisam de um período de adaptação para se desenvolverem na presença do ionóforo. Além disso, algumas espécies gram-positivas podem ser tão resistentes quanto às gram-negativas (Callaway \& Russell, 2000); um exemplo é a espécie Clostridium aminophilum, uma bactéria produtora de amônia e que contribui na degradação de aminoácidos no rúmen, que, em estudos in vitro, foi inibida pela monensina (Chen \& Russell, 1989), enquanto, em estudos in vivo, não pôde ser eliminada do rúmen quando utilizado o mesmo produto (Krause \& Russell, 1996).

Diferente deste experimento, Yang \& Russell (1993) observaram que a adição de monensina à dieta de vacas alimentadas com diferentes níveis de farelo de soja $(0,0 ; 1,0$; e $2,0 \mathrm{~kg} / \mathrm{dia}$ ) aumentou a proporção molar de propionato e diminuiu a relação acetato:propionato sem interferir na concentração total de AGV, efeito mais marcante nos animais alimentados com maior quantidade de farelo de soja. Os efeitos deste produto sobre a fermentação ruminal também foram confirmados por Ramazin et al. (1997), Surber \& Bowman (1998), Ruiz et al. (2001) e Broderick (2004).

O uso de monensina em dietas contendo lipídeos insaturados, como aquelas contendo soja ou caroço de algodão, pode ter efeito benéfico adicional, pois a monensina diminui a transformação desses lipídeos em ácidos graxos livres (Van Nevel \& Demeyer, 1995), altamente tóxicos para os microrganismos ruminais (Tedeschi et al., 2003). Ives et al. (2002) não constataram alterações significativas nas proporções molares dos ácidos orgânicos ao utilizarem a monensina + tilosina ou virginamicina em dieta basicamente concentrada. A avaporcina, outro antibiótico nãoionóforo, não alterou significativamente as proporções molares dos AGV, mas a concentração molar de ácido propiônico tendeu a aumentar com a adição deste produto e a de ácido butírico tendeu a diminuir, além de proporcionar redução significativa nas concentrações molares de isobutirato e isovalerato (Haimoud et al., 1995).

Resultados diferentes foram obtidos por Marounek et al. (1998), que constataram aumento da concentração molar de ácido propiônico com a utilização da avaporcina, bacitracina ou tilosina. A flavomicina e a virginamicina, no entanto, aumentaram a concentração de ácido butírico. Além disso, a flavomicina, tilosina e virginamicina causaram diminuição bastante significativa na concentração total de AGV.

Não foram observados efeitos significativos da monensina ou da enramicina sobre o $\mathrm{pH}$ ruminal. Ruiz et al. (2001) também não observaram efeitos sobre o pH ruminal de vacas leiteiras alimentadas com forragem fresca e sob suplementação com monensina, assim como Fredrickson et al. (1993), Yang \& Russell (1993), Mass et al. (2001), Nussio et al. (2003) e Osborne et al. (2004) ao utilizarem monensina, Darden et al. (1985), ao utilizarem monensina ou lasalocida, Rodrigues et al. (2000), ao utilizarem lasalocida, e Haimoud et al. (1995), ao utilizarem avaporcina. 
Os dados obtidos neste estudo contradizem os descritos por outros autores, como Lana \& Russell (1997), Green et al. (1999) e Surber \& Bowman (1998) ao utilizarem a monensina, que observaram aumentos do $\mathrm{pH}$ do líquido ruminal. $\mathrm{O}$ aumento do $\mathrm{pH}$ ruminal seria causado, de acordo com Osborne et al. (2004), primariamente pela inibição das bactérias produtoras de lactato, que proliferam em abundância sem a presença da monensina. Em muitos experimentos com animais alimentados com altas quantidades de carboidratos rapidamente fermentáveis, a monensina foi importante para o funcionamento normal do rúmen por manter o $\mathrm{pH}$ ideal (Owes et al., 1998).

Tratamento e tempo interagiram para a concentração ruminal de nitrogênio amoniacal $(P=0,0109)$, embora nenhum efeito significativo de tratamento tenha sido observado na análise em cada tempo separadamente (Figura 1C).

Independentemente do tratamento, observou-se redução acentuada dos valores de nitrogênio amoniacal nas coletas realizadas entre 4 e 6 horas após a primeira refeição do dia; esta variabilidade é comum em ruminantes alimentados de forma intermitente (Mehres et al., 1977). Há ainda outros fatores que podem influenciar este parâmetro, como local de amostragem no rúmen, tempo após a alimentação, período de estocagem da amostra, conservante ácido utilizado, método de determinação e tipo de dieta (Wohlt et al., 1976). Bergen \& Bates (1984) afirmaram ainda que é comum observar efeitos da monensina em diminuir as concentrações de nitrogênio amoniacal. Essa redução é causada pela sua atuação sobre as bactérias gram-positivas, uma vez que estas bactérias possuem alta especificidade para a produção de amônia, ao contrário das bactérias gram-negativas, resistentes a monensina. Esta explicação também foi dada por Russell et al. (1988) e Chen \& Russell (1989) ao constatarem redução da produção de amônia causada pelo antibiótico não-ionóforo flavomicina. Em animais tratados com avaporcina ou monensina, a concentração de nitrogênio amoniacal foi, respectivamente, 35,6 e 53,0\% menor que a de animais que não receberam nenhum produto (Haimoud et al., 1995).

Rodrigues et al. (2004), utilizando diferentes doses de monensina e diferentes proporções concentrado/volumoso, observaram redução nos valores de nitrogênio amoniacal, independentemente dos níveis de monensina ou fibra na dieta. Mwenya et al. (2004) verificaram redução no valor de nitrogênio amoniacal em novilhas alimentadas com monensina. Estudos com bovinos alimentados com altas quantidades de grãos (Haimoud et al., 1995) e com alta quantidade de volumosos (Ruiz et al., 2001) comprovaram que os ionóforos efetivamente diminuem a concentração de amônia no fluido ruminal. A monensina diminui a atividade proteolítica obrigando as bactérias a fermentar carboidratos (Russell \& Strobel, 1989). Conseqüentemente, a concentração de amônia no rúmen pode diminuir, ocasionando redução na degradação de proteína e aminoácidos dos alimentos (Mwenya et al., 2004).

Os resultados obtidos nesta pesquisa condizem com os de outros experimentos, nos quais não houve alterações significativas da monensina sobre a concentração de nitrogênio amoniacal; entre eles, destacam-se os dados obtidos por Ramazin et al. (1997), em vacas leiteiras alimentadas com dietas com 30 ou 50\% de concentrados, Garcia-Lopez et al. (1996), utilizando meio de cultura contendo dietas com 0, 50 ou 90\% de concentrados, e Lana \& Russell (1997), utilizando dietas com 0, 50 ou 100\% de alfafa. Esses autores observaram efeitos da monensina apenas nos animais alimentados com a dieta com $100 \%$ de alfafa, nos quais houve aumento do nitrogênio amoniacal.

Nenhum dos antibióticos testados alterou o padrão de comportamento alimentar (Tabela 4). De forma geral, os animais passaram aproximadamente $20 \%$ do seu tempo comendo, $25 \%$ do tempo ruminando e 50 a $55 \%$ do tempo em ócio.

Baile et al. (1979) afirmaram que ruminantes são capazes de detectar a presença do aditivo comercial contendo monensina, uma vez que o sabor é suficiente para causar aversão imediata ao produto, o que não ocorre com a monensina sódica propriamente dita. Além disso, esse efeito é observado principalmente em dietas predominantemente concentradas. Esta informação é bastante interessante se considerada a afirmação de Chalupa (1977) de que "não existe qualquer dado disponível a respeito dos efeitos dos ionóforos sobre o comportamento alimentar ou se alguma parte da redução do consumo é decorrente da aversão condicionada, dos fatores gustativos ou olfatórios ou do mal-estar do animal.

Baile et al. (1979) e Erickson et al. (2004), ao final de dois estudos nos quais os animais foram alimentados com dietas

Tabela 4 - Proporção média do tempo, ao longo do dia, gasto pelos animais comendo, ruminando e descansando

\begin{tabular}{lcccccc}
\hline \multirow{2}{*}{ Item } & \multicolumn{3}{c}{ Tratamento $^{1}$} & & & \\
\cline { 2 - 4 } & C & E & M & Média & CV (\%) & P \\
\hline Comendo, \% & 18,5 & 22,6 & 21,2 & 20,8 & 28,4 & ns \\
Ruminando, \% & 25,0 & 30,5 & 22,3 & 25,9 & 32,5 & ns \\
Ócio, \% & 65,5 & 46,9 & 56,5 & 53,3 & 19,9 & ns \\
\hline
\end{tabular}

${ }^{1} \mathrm{C}=$ controle $\mathrm{E}=$ enramicina; $\mathrm{M}=$ monensina . 
contendo monensina ou lasalocida ou alimento sem ionóforos, concluíram, em ambos os estudos, que os bovinos preferem o alimento sem a presença dos produtos. Constataram ainda preferência aos alimentos contendo lasalocida sobre aqueles contendo monensina. Em bezerros recémnascidos recebendo monensina, não foi possível notar qualquer aversão ao alimento, provavelmente pela nãoassociação do produto ao alimento (Salles \& Lucci, 2000).

Artigos científicos sobre a atuação da enramicina sobre os parâmetros testados neste experimento não são encontrados na literatura.

\section{Conclusões}

Em animais alimentados com dietas predominantemente concentradas com cana-de-açúcar como único volumoso, não foi possível comprovar os efeitos benéficos da monensina ou da enramicina, nas doses utilizadas, no consumo de matéria seca, na fermentação ruminal e no comportamento alimentar em bovinos.

\section{Agradecimento}

Aos funcionários Everson Lázaro e Gilmar Botteon, pelo cuidado com os animais, e aos técnicos Ari de Castro, Gilson de Godoy, Simi Aflalo e Isabel Ramos, pela ajuda com as análises laboratoriais.

\section{Literatura Citada}

BAILE, C.A.; McLAUGHLin, C.L.; POTTER, E.L. et al. Feeding behavior changes of cattle during introduction of monensin with roughage or concentrate diets. Journal of Animal Science, v.48, n.6, p.1501-1508, 1979.

BEEDE, D.K.; BATES, D.B.; HIRCHERT, E.M. et al. Lactational performance of midlactation Holstein cows fed lasalocid. Journal of Animal Science, v.63, p.417, 1986 (suppl.).

BERGEN, W.G.; BATES, D.B. Ionophores: their effect on production efficiency and mode of action. Journal of Animal Science, v.58, n.6, p.1465-1483, 1984.

BEZERRA, P.S.; DRIEMEIER, D.; LORETTI, A.P. et al. Monensin poisoning in Brazilian horses. Veterinary and Human Toxicology, v.41, n.6, p.383-385, 1999.

BRODERICK, G.A. Effect of low level of monensin supplementation on the production of dairy cows fed alfafa silage. Journal of Dairy Science, v.87, n.2, p.359-368, 2004.

CALLAWAY, T.R.; RUSSELL, J.B. Selection of a highly monensinresistant Prevotella bryantii sub-population with altered outer membrane characteristics. Applied and Environmental Microbiology, v.65, n.11, p.4753-4759, 1999.

CALLAWAY, T.R.; RUSSELL, J.B. Variations in the ability of ruminal Gram negative Prevotella species to resist monensin. Current Microbiology, v.40, n.3, p.185-190, 2000.

CHALUPA, W. Manipulating rumen fermentation. Journal of Animal Science, v.45, n.3, p.585-599, 1977.

CHEN, G.; RUSSELL, J.B. Sodium-dependent transport of branchedchain amino acids by a monensin-sensitive ruminal
Peptostreptococcus. Applied and Environmental Microbiology, v.55, n.10, p.2658-2663, 1989.

DARDEN, D.E.; MERCHEN, N.R.; BERGER, L.L. et al. Effects of avoparcin, lasalocid and monensin on sites of nutrient digestion in beef steers. Nutrition Reports International, v.31, n.4, p.979-989, 1985.

ERICKSON, P.S.; DAVIS, M.L.; MURDOCK, C.S. et al. Ionophores taste preference of dairy heifers. Journal of Animal Science, v.82, n.11, p.3314-3320, 2004.

ERWIN, E.S.; MARCO, G.J.; EMERY, E.M. Volatile fatty acid analyses of blood and rumen fluid by gas chromatography. Journal of Dairy Science, v.44, n.9, p.1768-1771, 1961.

FOLDAGER, J. Protein requirement and non protein nitrogen for high producing cow in early lactation. East Lasing: Michigan State University, 1977. 167p. Thesis (Doctor in Animal Science) - Michigan State University, 1977.

FREDRICKSON, E.L.; GALYEAN, M.L.; BRANINE, M.E. et al. Influence of ruminally dispensed monensin and forage maturity on intake and digestion. Journal of Range Management, v.46, n.3, p.214-220, 1993.

GALLARDO, M.R.; CASTILLO, A.R.; BARGO, F. et al. Monensin for lactating dairy cows grazing mixed-alfalfa pasture and suplemented with partial mixed ration. Journal of Dairy Science, v.88, n.2, p.644-652, 2005.

GARCIA, C.C.G.; MENDOZA, M.G.D.; GONZÁLEZ, M.S. et al. Effect of a yeast culture (Saccharomyces cerevisiae) and monensin on ruminal fermentation and digestion in sheep. Animal Feed Science and Technology, v.83, n.2, p.165$170,2000$.

GARCIA-LOPEZ, P.M.; KUNG, L.; ODOM, J.M. In vitro inhibition of microbial methane production by 9,10-Anthrarquinone. Journal of Animal Science, v.74, n.9, p. 2276-2284, 1996.

GOODRICH, R.D.; GARRET, J.B.; GAST, D.R. Influence of monensin on the performance of cattle. Journal of Animal Science, v.58, n.6, p.1484-1498, 1984.

GREEN, B.L.; McBRIDE, B.W.; SANDALS, D. et al. The impact of a monensin controlled-release capsule on subclinical ketosis in the transition dairy cow. Journal of Dairy Science, v.82, n.2, p.333-342, 1999.

HAIMOUD, D.A; VERNAY, M.; BAYOURTHE, C. et al. Avoparcin and monensin effects on the digestion of nutrients in dairy cows fed a mixed diet. Canadian Journal of Animal Science, v.75, n.2, p.379-385, 1995.

HAN, H.; HUSSEIN, H.S.; GLIMP, H.A. et al. Carbohydrate fermentation and nitrogen metabolism of a finishing beef diet by ruminal microbesin continuous cultures as affected by ethoxyquin and (or) supplementation of monensin and tylosin. Journal of Animal Science, v.80, n.4, p.1117 1123, 2002.

IVES, S.E.; TITGEMEYER, E.C.; NAGAJARA, T.G. et al. Effects of virginiamycin and monensin plus tylosin on ruminal protein metabolism in steers fed corn-based finishing diets with or without wet corn gluten feed. Journal of Animal Science, v.80, n.11, p.3005-3015, 2002.

KAWAKAMI, M.; NAGAI, Y. Anti-microbial activities of Enduracin (Enramycin) in vitro and in vivo. The Journal of Antibiotcs, v.24, n.9, p.583-586, 1971.

KRAUSE, D.O.; RUSSELL, J.B. An rRNA approach for assessing the hole of obligate amino acid-fermenting bacteria in ruminal amino acid degradation. Applied and Environmental Microbiology, v.62, n.3, p.815-821, 1996.

LANA, R.P.; RUSSELL, J.B. Effect of forage quality and monensin on the ruminal fermentation of fistulaled cows fed continuosly at a constant intake. Journal of Animal Science, v.75, n.1, p.224-229, 1997.

LUCCI, C.S. Nutrição e manejo de bovinos leiteiros. 1.ed. São Paulo: Manole, 1997. 169p.

MAROUNEK, M.; DUSKOVA, D.; SKRIVANOVA, V. Effect of non-ionophore feed antibiotics on in vitro fermentation in the 
ovine rumen and rabbit caecum. Journal of Agricultural Science, v.130, n.1, p.115-118, 1998.

MASS, J.A.; WILSON, G.F.; McCUTCHEON, S.N. et al. The effect of season and sodium monensin on the digestive characteristics of autumn and spring pasture fed to sheep. Journal of Animal Science, v.79, n.4, p.1052-1058, 2001.

MEHRES, A.Z.; ØRSKOV, E.R.; McDONALD, I. Rates fermentation in relation to ammonia concentration. The British Journal of Nutrition, v.38, n.3, p.437-443, 1977.

MWENYA, B.; SAR, C.; SANTOSO, B. et al. Comparing the effects of ß1-4 galacto-oligosaccharides and L-Cysteine to monensin on energy and nitrogen utilization in steers fed a very high concentrate diet. Animal Feed Science and Technology, v.118, n.1, p.19-30, 2004.

NATIONAL RESEARCH COUNCIL - NRC. Nutrient requirements for dairy cattle. 6.ed. Washington, D.C.: National Academy of Sciences, 1989. 157p.

NUSSIO, C.M.B.; SANTOS, F.A.P.; ZOPOLLATTO, M. et al. Parâmetros de fermentação e medidas morfométricas dos compartimentos ruminais de bezerros leiteiros suplementados com milho processado (floculado vs. laminado a vapor) e monensina. Revista Brasileira de Zootecnia, v.32, n.4, p.1021-1031, 2003.

OSBORNE, J.K.; MUTSVANGWA, T.; ALZAHAL, O. et al. Effects of monensin on ruminal forage degradability and total tract diet digestibility in lactating dairy cows during grain-induced subacute ruminal acidosis. Journal of Dairy Science, v.87, n.6, p.1840-1847, 2004.

OWES, F.N.; SECRIST, D.S.; HILL, W.J. et al. Acidosis in cattle: a review. Journal of Animal Science, v.76, n.1, p.275-286, 1998.

PLAZIER, J.C.; MARTIN, A.; DUFFIED, T. et al. Effect of a prepartum administration of monensin in a controlled-release capsule on apparent digestibilities and nitrogen utilization in transition dairy cows. Journal of Dairy Science, v.83, n.12, p.2918-2925, 2000.

PRANGE, R.W.; DAVIS, C.L.; CLARK, J.H. Propionate production in the rumen of Holstein steers fed either a control or monensin supplemented diet. Journal of Animal Science, v.46, n.4, p.1120-1124, 1978.

RAMAZIN, M.; BAILONI, L.; SCHIAVON, S. et al. Effect of monensin on milk production and efficiency of dairy cows fed two diets differing in forage to concentrate ratios. Journal of Dairy Science, v.80, n.8, p.1136-1142, 1997.

RODRIGUES, P.H.M.; LUCCI. C.S.; CASTRO, A.L. Efeitos da lasalocida sódica e proporção volumoso/concentrado sobre a fermentação ruminal em vacas secas. Brazilian Journal of Veterinary Research and Animal Science, v.37, n.3, p.259264, 2000.

RODRIGUES, P.H.M.; MATTOS, W.R.S.; MELOTTI, L. et al. Monensina e digestibilidade aparente em ovinos alimentados com proporções de volumoso e concentrado. Scientia Agricola, v.58, n.3, p.449-455, 2001

RODRIGUES, P.H.M.; MATTOS, W.R.S.; MEYER, P.M. et al. Effects of monensin level and roughage/concentrate ratio on ruminal fermentation in bovines. Journal of Animal and Feed Science, v.13, p.195-198, 2004 (suppl. 1).

RUIZ, R.; ALBRECHT, G.L.; TEDESCHI, L.O. et al. Effect of monensin on the performance and nitrogen utilization of lactating dairy cows consuming fresh forage. Journal of Dairy Science, v.84, n.7, p.1717-1727, 2001.

RUSSELL, J.B.; STROBEL, H.J. Minireview: the effect of ionophores on ruminal fermentation. Applied and Environemental Microbiology, v.55, n.1, p.1-6, 1989.

RUSSELL, J.B.; STROBEL, H.J.; CHEN, G. The enrichment and isolation of a ruminal bacterium with a very high specific activity of ammonia production. Applied and Environmental Microbiology, v.54, n.4, p.872-878, 1988.

SALLES, M.S.V.; LUCCI, C.S. Monensina para bezerros ruminantes em crescimento acelerado. Revista Brasileira de Zootecnia, v.29, n.2, p.573-581, 2000.

STATISTICAL ANALYSIS SYSTEM - SAS. SAS user's guide: statistics. 5.ed. Cary: SAS Institute, 1985. 441p.

SPEARS, J.W. Ionophores and nutrient digestion and absorption in ruminants. Journal of Nutrition, v.120, n.6. p.632-638, 1990 .

SURBER, L.M.M.; BOWMAN, J.G.P. Monensin effects on digestion of corn or barley high-concentrate diets. Journal of Animal Science, v.76, n.7, p.1945-1954, 1998.

TEDESCHI, L.O.; FOX, D.G.; TYLUTKI, T.P. Potential environmental benefits of ionophores in ruminants diets. Journal of Environmental Quality, v.32, n.5, p.1591-1602, 2003.

THORNTON, J.H.; OWENS, F.N. Monensin supplementation and in vivo methane production by steers. Journal of Animal Science, v.52, n.3, p.628-634, 1981.

Van der MERWE, B.J.; DUGMORE, T.J.; WALSH, K.P. The effect of flavophospholipol (Flavomycin) on milk prodution and milk urea nitrogen concentration of grazing dairy cows. South Africa Journal of Animal Science, v.31, n.2, p.101-105, 2001.

Van NEVEL, C.J.; DEMEYER, D.I. Lipolysis and biohydrogenation of soybean oil in the rumen in vitro: inhibition by antimicrobials. Journal of Dairy Science, v.78, n.12, p.2797-2806, 1995.

WOHLT, J.E.; CLARK, J.H.; BLAISDELL, F.S. Effects of sampling location, time and method of concentration of ammonia nitrogen in the rumen. Journal of Dairy Science, v.59, n.3, p.459-464, 1976.

YANG, C.M.J.; RUSSEL, J.B. The effect of monensin supplementation on ruminal ammonia accumulation in vivo and the numbers of amino acid-fermenting bacteria. Journal of Animal Science, v.71, n.12, p.3470-3476, 1993 